\title{
Effect of Growth Ring Angle on Lateral Enlargement of Compressed Cryptomeria japonica Wood Impregnated with Polyethylene Glycol
}

\author{
Chikara Mizoguchi, ${ }^{a}$ Hiroki Sakagami, ${ }^{\text {, } *}$ Noboru Fujimoto, ${ }^{b}$ and Tetsuya Nakao ${ }^{b}$ \\ The lateral enlargement perpendicular to the compressive direction for \\ small thin boards of Cryptomeria japonica was investigated to evaluate the \\ effects of density and compressive directions to the radial (plane-sawn \\ board) and 45 degrees of tilt to the radial (45 sawn board). Samples were \\ impregnated with 200 and 20,000 molecular weight polyethylene glycol \\ (PEG). The enlargement perpendicular to the fiber direction with \\ deformation was obtained for heartwood and sapwood specimens treated \\ only with PEG20,000. The compression ratio of specimens treated with \\ PEG 20,000 exceeded the void volumes regardless of the wood density. \\ Enlarged specimens of both sapwood and heartwood showed the \\ inflection points in the force-compression ratio curve and no correlation \\ between the compressive directions and lateral enlargement of \\ specimens. In the local area showing the largest deformation, however, a \\ weak positive correlation from plane-sawn boards and weak negative \\ correlation from $45^{\circ}$ sawn boards between the angles of compressive \\ direction to growth ring and lateral enlargement were derived. Microfocus \\ X-ray computer tomography in these areas showed the different \\ morphological compressive deformations. The cells in the 45 sawn board \\ were forced out due to each cell moving, whereas the radially arranged \\ ones in the plane sawn board buckled under compression.
}

Keywords: Compression; Enlargement; Polyethylene glycol; Growth ring angle; Cryptomeria japonica

Contact information: a: Graduate School of Bioresource and Bioenvironmental Sciences, Kyushu

University, Fukuoka 819-0395, Japan; b: Department of Agro-environmental Sciences, Faculty of

Agriculture, Kyushu University, Fukuoka 819-0395, Japan;

*Corresponding author: h-sakagami@agr.kyushu-u.ac.jp

\section{INTRODUCTION}

Wood, which is comprised of a honeycomb porous structure, has many characteristics that are useful for multiple applications, including civil engineering, construction, and furniture. Wood is composed of bundles of hollow tubular fiber cells that are arranged in radial directions after divided from cambium cells. They are more easily crushed by side pressure than those in a longitudinal fiber direction. The strength of compression parallel to fiber direction is nearly ten times as high as that perpendicular to the fiber direction in some species (Wood Handbook 1999). Low-density wood can be modified to high-density wood by compression, using this characteristic.

Density affects wood compression and the mechanical properties of wood. Lowdensity wood with many cavities can be compressed easily, whereas high-density wood with no space to allow compression is harder to compress. Therefore, the high-density area resists compression when both low- and high-density parts coexist. In wood such as softwood, earlywood is simply compressed before latewood in a radial compression 
because they are arranged one after the other in a radial direction, like a sandwich. In general, the cells of earlywood have thin cell walls and larger cavities that are easy to crush (Iida et al. 1984; Ioue et al. 1992; Watanabe et al. 1998), and they recover with moisture and boiling up to $70 \%$ of the compression ratio (Ioue et al. 1993a) without any damage or divisions of cells. However, the recovery of specimens can be impeded by special treatments, including chemicals (Inoue et al. 1991, 1993c; Fukuta et al. 2008), hygrothermal (Ioue et al. 1993a), and steaming (Inoue et al. 1993b). High-density wood modified by these methods exhibits enhanced hardness (Inoue et al. 1991, 1993b), and is used for flooring and furniture. In recently developed compression technology, compressed and uncompressed layers could be controlled by treatment time of soaking in water, pressing, and heating (Gao et al. 2016).

The maximum of compression ratio without causing any damage depends on the density of the wood being treated. For instance, an $80 \%$ compression ratio causes some damage to Cryptomeria japonica, resulting in low recovery (Inoue et al. 1993a). The density of this specimen under air-dried condition and growth ring width were 0.35 and $3.16 \mathrm{~mm}$, respectively. However, when specimens were treated with certain chemical additives that can reduce the friction between cells, deformation increased due to slipping occurring during compression that exceeded the ratio of the cavity.

Bulk woods impregnated with polyethylene glycol (PEG), phenol monomers, and melamine formaldehyde can be extruded or injected by enlargement, with concurrent cell slippage (Miki et al. 2014a,b,c). This enlargement is reproduced when the woods are saturated with water under specific hydrothermal conditions (Miki et al. 2017). This phenomenon may be due to softening intercellular regions between wood cells with high temperatures in the presence of water.

In these studies, wood materials were mainly compressed in the radial direction. However, the compression in a different direction might affect the enlargement because wood is composed of different kinds of cells with anisotropic shapes that are arranged to longitudinal, radial, and tangential directions. Additionally, the friction between two slipping substances are generally influenced by the viscosity of filled lubricant as well as the reactions between cell walls and chemicals of lubricant might affect the enlargement. Penetration of lubricant into the cell wall also might affect the friction. In this study, the lateral enlargement was investigated perpendicular to the compressive direction of Cryptomeria japonica wood impregnated with two types of low and high molecular PEG with similar chemical reaction but different molecular weights and viscosity. This was studied to evaluate the effects of density and two kinds of compressive directions. Separate specimens of sapwood and heartwood with different air permeability were compressed.

\section{EXPERIMENTAL}

\section{Wood Specimens}

A $\log$ of Cryptomeria japonica D. don was used, which had been harvested in the Kasuya research forest of Kyushu University in Japan. The diameter of the log was 400 $\mathrm{mm}$. A schematic image of prepared specimens is shown in Fig. 1. The 400-mm-long specimens in fiber direction were obtained from sapwood and heartwood in the log. Two types of specimens were prepared from each place: (1) plane-sawn board with growth rings on the cross surface arranged parallel to the surface, and (2) $45^{\circ}$ sawn boards with growth rings on the cross surface arranged at around $45^{\circ}$ tilted to the surface. 


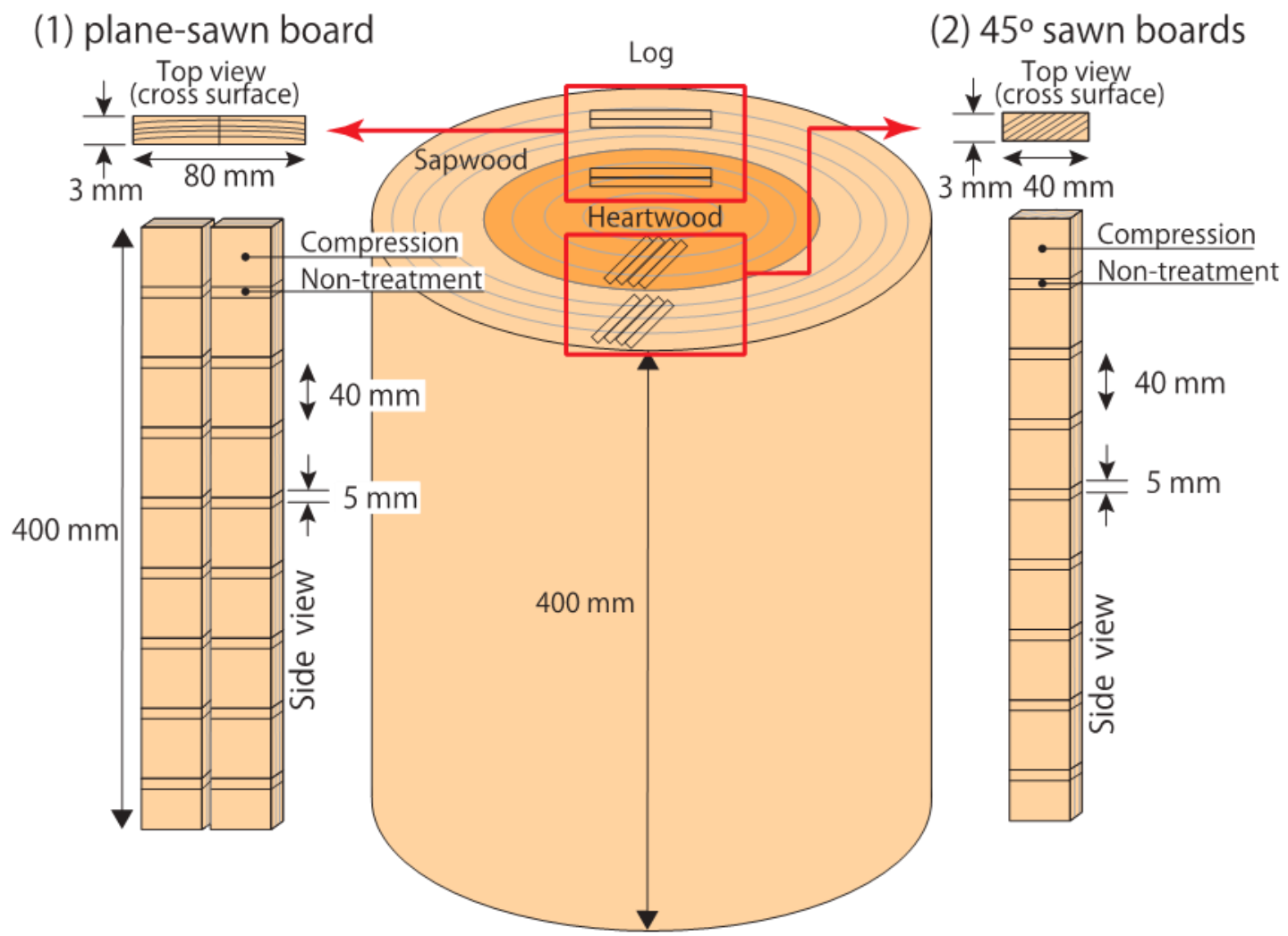

Fig. 1. Schematic diagram of cutting specimens. (1) Plane-sawn board; growth rings on the cross surface were arranged parallel to the surface, (2) $45^{\circ}$ sawn boards; growth rings on the cross surface were arranged at around $45^{\circ}$ (degree) to the surface. The two types of specimens were derived from sapwood and heartwood.

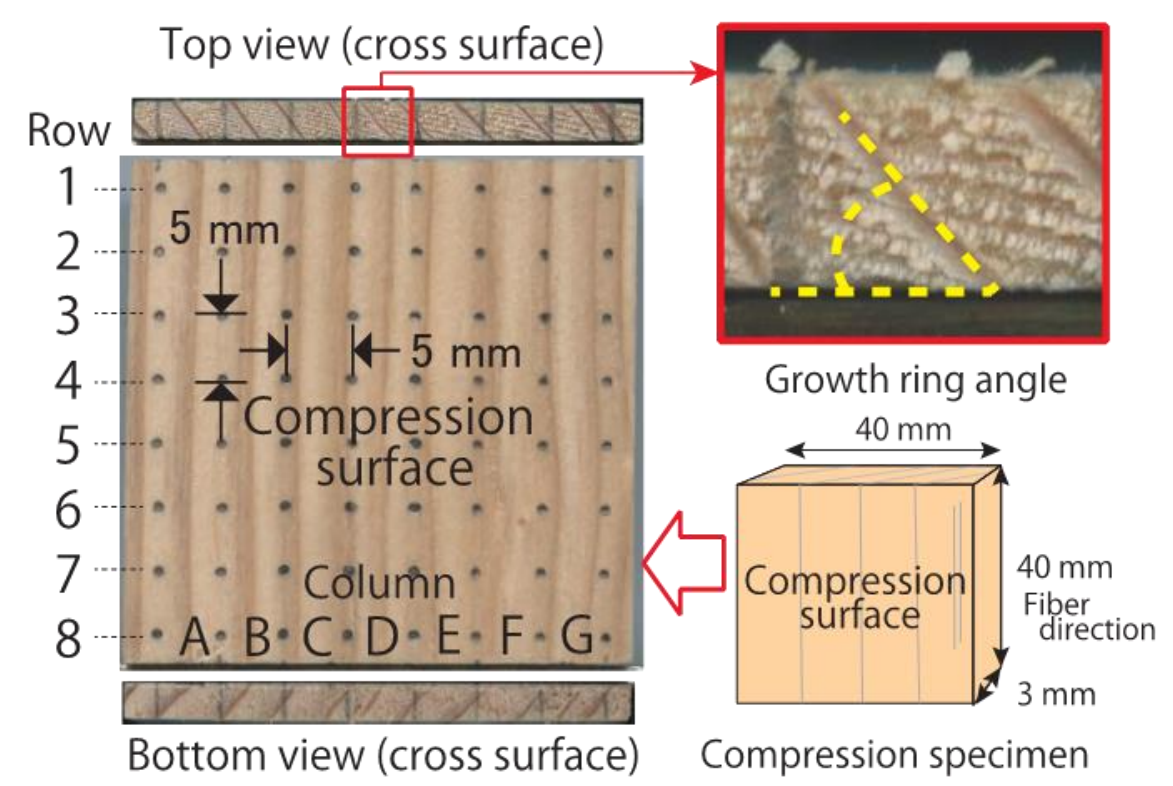

Fig. 2. Preparation of specimens for compressing. Dots and lines were marked every $5 \mathrm{~mm}$ on the surface and cross surfaces to evaluate the width deformation ratio due to compression. The growth ring angle to the surface was measured. 
Plane-sawn boards were cut to $80 \mathrm{~mm}$ width and $5 \mathrm{~mm}$ thickness. In comparison, $45^{\circ}$ sawn boards were cut to $40 \mathrm{~mm}$ width and $5 \mathrm{~mm}$ thickness. Plane-sawn boards were split into two boards with the same dimensions as the $45^{\circ}$ sawn boards. They were finally finished to $3 \mathrm{~mm}$ thickness with a planer after all boards had been dried at room temperature for more than 2 weeks. The sawn specimens were longitudinally cross-cut into two parts, 40-mm-long specimens for compressing and 5-mm-long specimens for uncompressing. Dots and lines were marked every $5 \mathrm{~mm}$ on the compression surface and cross surfaces of specimens to evaluate the width deformation ratio due to compression (Fig. 2)

\section{Analysis of the Specimen before Compressing}

Specimens for compressing were conditioned at $25{ }^{\circ} \mathrm{C}$ and $65 \%$ relative humidity (RH) for 2 days. The weight and three dimensions (length, width, and thickness) were measured with a valance and digital caliper. Surface images of the specimens were obtained with a scanner (GT-X970, Epson, Nagano, Japan) for 850 dpi resolution before compressing. The distance between dots marked on the surface perpendicular to the fiber direction was measured using image analysis software (WinROOF, Mitani Corporation, Tokyo, Japan). The angle of the growth ring to the plane on both cross surfaces (top and bottom) was measured using scanned images as shown in Fig. 2. When more than one growth ring was present between line marks due to narrow growth ring width, the central one was selected for the measurement. The angle of ray parenchyma distributed perpendicular to the growth ring was measured with a stereomicroscope (SZX7, Olympus Corporation, Tokyo, Japan) when no growth rings were visible between the lines. The measurable growth ring width and latewood percentage for sapwood and heartwood was measured with non-treatment specimens using a confocal laser scanning microscope (TCS SP8, Leica Microsystems GmbH, Wetzlar, Germany).

\section{Impregnation with Polyethylene Glycol (PEG)}

The weight and the three dimensions of the compression specimens were measured after vacuum drying at $70{ }^{\circ} \mathrm{C}$ under approximately $0.9 \mathrm{kPa}$ for a day. Two types of PEG were purchased and used in this study to evaluate the effects of molecular weight and viscosity on the acceleration of enlargement. The molecular weights of two PEGs were 200 in the liquid condition and 20,000 in the solid condition at room temperature, purchased from FUJIFILM Wako Pure Chemical Corporation, Osaka, Japan. The prepared $30 \mathrm{wt} \%$ concentration of both PEGs diluted with distilled water were impregnated into specimens under the following different pressure conditions. The performed procedure was that the specimens were immersed in the respective PEG solutions under vacuum pressure (approximately $4.0 \mathrm{kPa}$ ) for an hour, and then kept under atmospheric pressure for 3 days to be sufficiently saturated. The weight and three dimensions under saturated conditions were measured again after excess PEG was wiped off the surface.

\section{Compression}

A universal testing machine (AG-110kN, Shimazu, Kyoto, Japan) was used to compress specimens that were held with steel plates heated to $160{ }^{\circ} \mathrm{C} \pm 5{ }^{\circ} \mathrm{C}$. A couple of aluminum foil sheets of $12 \mu \mathrm{m}$ thickness were placed between the steel plate and specimen to generate the same friction on the upper and bottom surfaces of the specimen. Specimens were pressed at a speed of $10 \mathrm{~mm}$ a minute on the surface perpendicular to fibers, and compression was stopped at $8.0 \times 10^{3} \mathrm{kgf}$. Two positions of the crosshead when it stopped at $8.0 \times 10^{3} \mathrm{kgf}$ with and without specimens were recorded to measure the compression 
ratio (equation 1). The plates were cooled to a temperature below $90{ }^{\circ} \mathrm{C}$ at room temperature, and then the pressure was released. The compressed specimens were conditioned at $25{ }^{\circ} \mathrm{C}$ and $65 \% \mathrm{RH}$ for 2 days.

\section{Analysis of the Specimens after Compression}

The weight and three dimensions of specimens after conditioning were measured. The compression ratio, recovery ratio after conditioning, and width deformation ratio were calculated with eq. (1), (2), and (3)

$$
\text { Compression ratio }=\left(H_{0}-D_{S}+D_{0}\right) / H_{0}
$$

where $H_{0}$ is the thickness of specimen before the compression test, $D_{S}$ is the displacement of crosshead with specimen when crosshead is stopped, and $D_{0}$ is the displacement of crosshead without specimen (contact point of upper and lower plates).

$$
\text { Recovery ratio }=\left(H_{R}-D_{S}+D_{0}\right) /\left(H_{0}-D_{S}+D_{0}\right)
$$

where $H_{R}$ is thickness of compressed specimens after conditioning,

$$
\text { Width deformation ratio }=W_{C} / W_{0}
$$

where $W_{C}$ is the the largest width of specimen after the compression test, and $W_{0}$ is the width of specimen before the compression test.

Surface images of conditioned specimens after compression were obtained using a scanner, and the distance between dots perpendicular to fiber direction were measured as described above. In case some dots, especially in heartwood impregnated with PEG20,000, were split or disappeared due to enlargement, the larger part that was one of visible remains was used for the measurements, while those that disappeared were excluded from the analysis. Expansion ratio between dots was calculated with Eq. 4.

$$
\text { Dots expansion ratio }=D_{C} / D_{0}
$$

where $D_{C}$ is the distance between dots after the compression test, and $D_{0}$ is the distance between dots before the compression test.

\section{Observation inside the Wood Structure}

Earlywood cells tend to be squashed when wood is compressed in a radial direction. The irreversible fracture or disorder of cell distribution was assumed to occur in extensively deformed specimens. In order to observe the microstructure of compressed specimens, tomographic images were obtained with X-ray micro computed tomography (CT) (SKYSCAN1172, Bruker Co., Billerica, MA, USA). Small portions from the most deformed local area in the specimen were obtained to acquire the images with high magnification. CT images of the cross section inside specimens were derived with the Xray images captured from the center at every $0.2^{\circ}$. The pixel size of the image was 1.08 $\mu \mathrm{m}$.

\section{RESULTS AND DISCUSSION}

\section{Compression Test}

The number of specimens, the average density after air-drying, and average angle of growth rings before compression are shown in Table 1. The density of air-dried 
heartwood was higher than that of sapwood. The growth ring angles of plain-sawn sapwood and heartwood specimens were approximately $13^{\circ}$ and $19^{\circ}$, respectively, while those of $45^{\circ}$ sawn board were around $46^{\circ}$. The average absorption of $30 \%$ PEG solution before compression, compression ratio, width deformation ratio, and recovery ratio are also shown. Sufficient PEG solution between 664 to $805 \mathrm{~kg} / \mathrm{m}^{3}$ was absorbed before compression, so that the fact that specimens were exuding PEG solution was evident during compression. The results of PEG200 and PEG20,000 showed different characteristics in some cases. Greater enlargement in the width direction with large deformation was observed for the specimens treated with PEG20,000 than those treated with PEG200 (Fig. 3 ). Compared with before compression, the width deformation ratios were 1.7 and 1.1 times greater for the PEG20,000 and PEG200 treatments, respectively. These trends were detected in both heartwood and sapwood. However, there was no significant difference between the sawn types of board and width deformation ratio for enlarged specimens treated with PEG20,000 ( $p$-value>0.05).
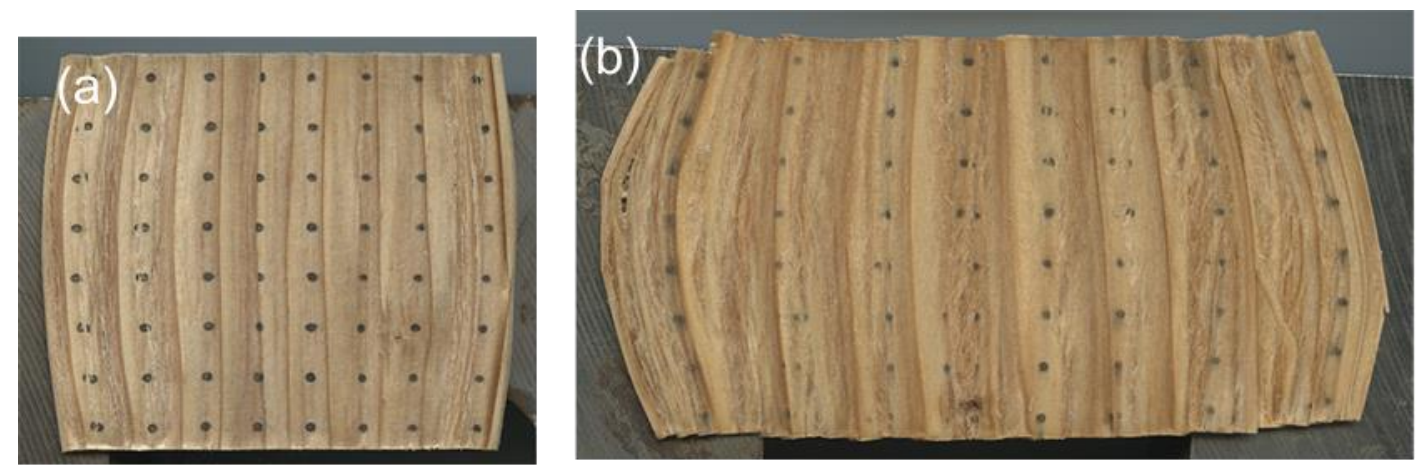

Fig. 3. Deformation of specimens after compressing. (a) Sapwood treated with PEG200 (b) sapwood treated with PEG20,000

In comparison, the compression ratio of deformed specimens in the PEG20,000 treatment was slightly higher than those in the PEG200 treatment. However, it was not possible to compare the compression ratio because it is impacted by the different densities of specimens, especially sapwood and heartwood used in this research. The compressible void space mainly occupied by cell lumens can be estimated with the density of wood. The relationships between compression ratio and density in air-dried conditions of specimens are shown in Fig. 4. A solid black line shows the relationship between void volume and the density in air-dried condition. This line was estimated from the void volumes calculated with the density of in oven-dried condition (vacuum drying at $70{ }^{\circ} \mathrm{C}$ ) and specific gravity of wood substance (1.5). The plots appeared to be distributed in parallel to the black line. Thus, the compression ratio was attributed to the density of specimens. Moreover, the larger compression ratio along with deformation of specimens treated with PEG20,000 exceeded a black line, regardless of the density of specimens for both sapwood and heartwood. Therefore, this deformation appeared to be caused by compression exceeding the void volume, whereas less of the void volume was compressed in specimens treated with PEG200. 
Table 1. Prepared Specimens and Deformation after Compressing

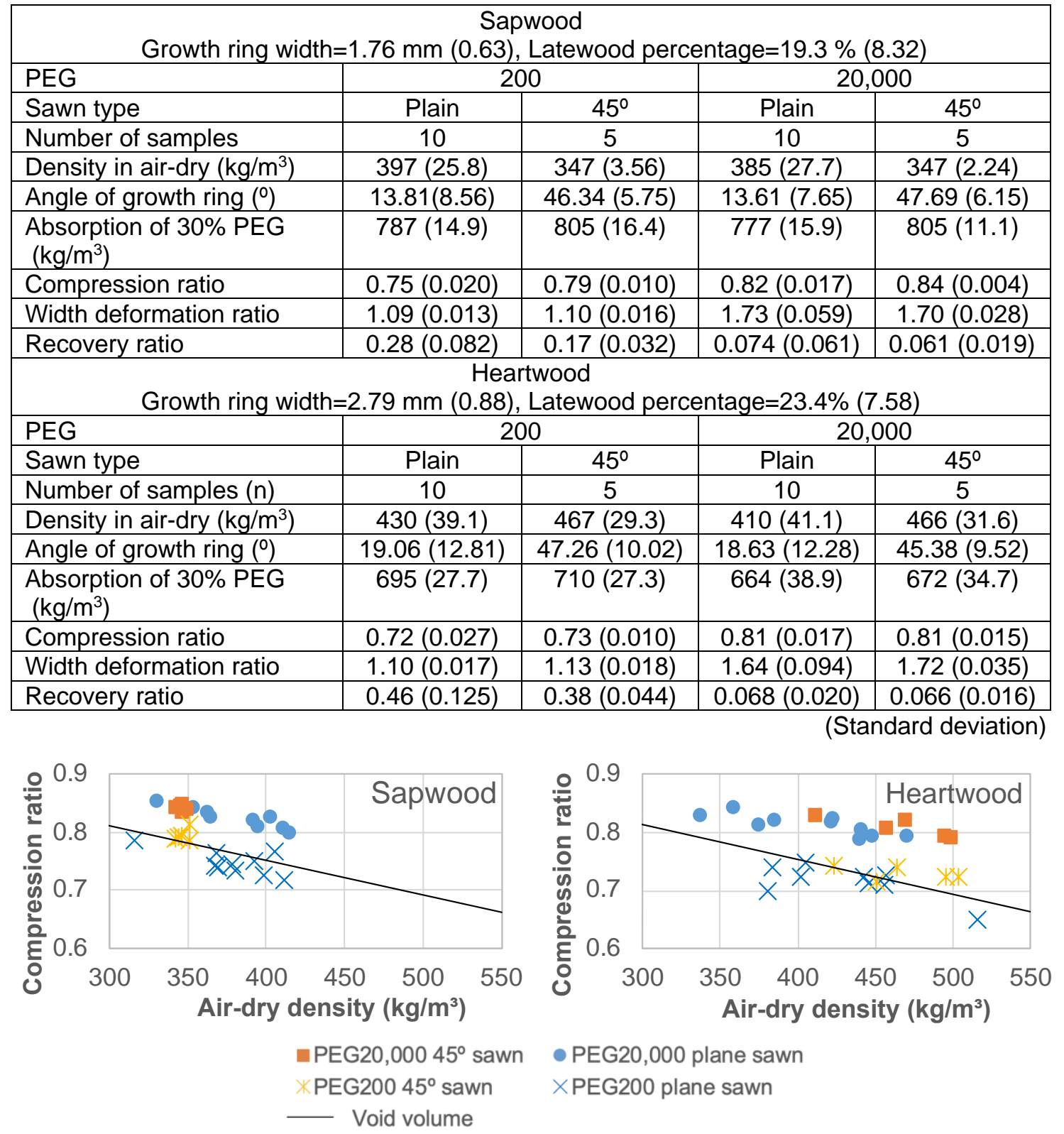

Fig. 4. Relationship between air dry density and compression ratio. The solid line shows the estimated void volume corresponding to air-dry density.

\section{Compressive Force}

The typical stress-strain curve shows a liner plateau in regions with low strain when wood specimens are compressed in a radial direction (Maiti et al. 1984; Reiterer and Stanzl-Tschegg 2001). In this region, the cells of earlywood with thin cell walls and plenty void space can be squash under low stress. Compressive stress noticeably increases when the squashed area changes to the latewood zone having the thicker cell wall. The relationship between compressive force and compression ratio of plane and $45^{\circ}$ sawn specimens treated with PEG200 and PEG20,000 is shown in Fig. 5. Compressive stress (force per square) was not derived due to amorphous deformation of specimen during compression. Compared with sapwood, the compressive force of heartwood increased at 
lower compression ratios. This phenomenon might be attributed to the resistance of enclosed vapor because permeability of liquids and air is low in heartwood (Erickson 1970; Flynn 1995), with Cryptomeria japonica being no exception (Fujii et al. 1997; Nagai and Taniguchi 2003). This tendency also referred to the higher recovery ratio of heartwood in Table 1. Both sapwood and heartwood specimens treated with PEG200 showed a similar exponential curve in the radial compression of non-treated general woods, though small increase in force by compression of earlywood just after initial compression was not apparent. This reason was considered to be the high compression speed and larger compressive area to thickness with slight roughness in this study. In comparison, the compressive force of specimens treated PEG20,000 had an inflection point, which formed a small peak at 0.3 to 0.4 of the compression ratio for both sawn specimens (sapwood and heartwood; Fig. 5 arrow). Miki et al. (2017) observed that the inflection point appeared on the stress-compression ratio curve for lateral deformed specimens compressed above 100 ${ }^{\circ} \mathrm{C}$. Irreversible large enlargement was assumed to occur in this inflection point. In fact, the recovery ratio of PEG20,000 in Table 1 was low compared with PEG200 with no inflection point. Miki et al. (2017) observed this inflection point between 0.75 and 0.85 of the compression ratio appearing after the volume of the lumen decreased when wood cells buckle and become denser. However, the inflection point in this study appeared between 0.3 and 0.4 of the compression ratios, which is before the void volume was completely squashed. This lower shift of inflection point was regarded as being due to the fact that the compressing speed was too fast to remove sufficient air and vapor of the inside from the void space.

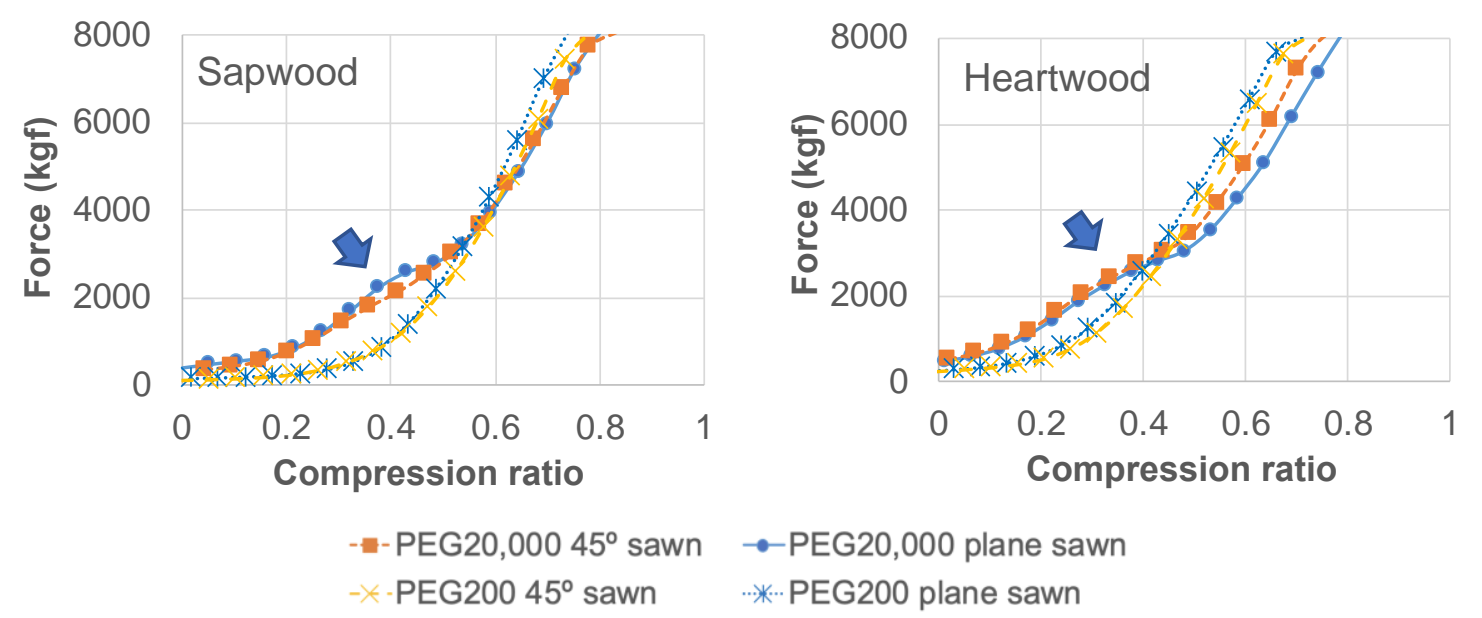

Fig. 5. Typical compression force-compression ratio curve

The lowered friction between moving substances (tracheids in this study) facilitates lateral enlargement by compression causing the sheering of cells in the intercellular layer. Though friction tends to be affected by the roughness of the surface, it can be ignored because adjacent cells are the same tracheid in this tree. However, the penetration of PEG into the interface of cells possibly serves as a lubricant, while the friction of dried nontreated wood during compression is assumed to be too high to permit slippage because cells bonded with each other at the intercellular layer. Moderate higher viscosity and faster velocity of moving substances can lower the coefficient of friction because they have enough space between surfaces, so that hydrostatic lubrication changes to hydrodynamic lubrication according to the Stribeck curve (Stribeck 1902; Bhushan 2002). Specimens 
treated with PEG20,000 that had an inflection point were considered to be enlarged perpendicular to fiber direction due to higher viscosity, contributing to a lower coefficient of friction. Additionally, the acceleration of the enlargement with the higher molecular weight of PEG20,000 might generate more lubricant space for hydrodynamic lubrication due to the residue of PEG on the interface of cells without penetrating into cell walls. This reason can be supported by the reports; more than 3,000 molecular weight of PEG cannot penetrate into the cell wall (Tarkow et al. 1966); and cell wall bulking of PEG200 was higher than that of PEG1,500 (Wallstrom and Lindberg 1999).

\section{Local Deformation and Growth Ring Angle}

Specimens treated with PEG 20,000 were greatly deformed in the lateral direction showing 1.64 to 1.73 of width deformation ratio (Table 1). However, there was no correlation between the sawn types and width deformation ratio. Observing the compressed surface of specimens, the large and slight deformed areas appeared to coexist within the same specimens (Fig. 3b).
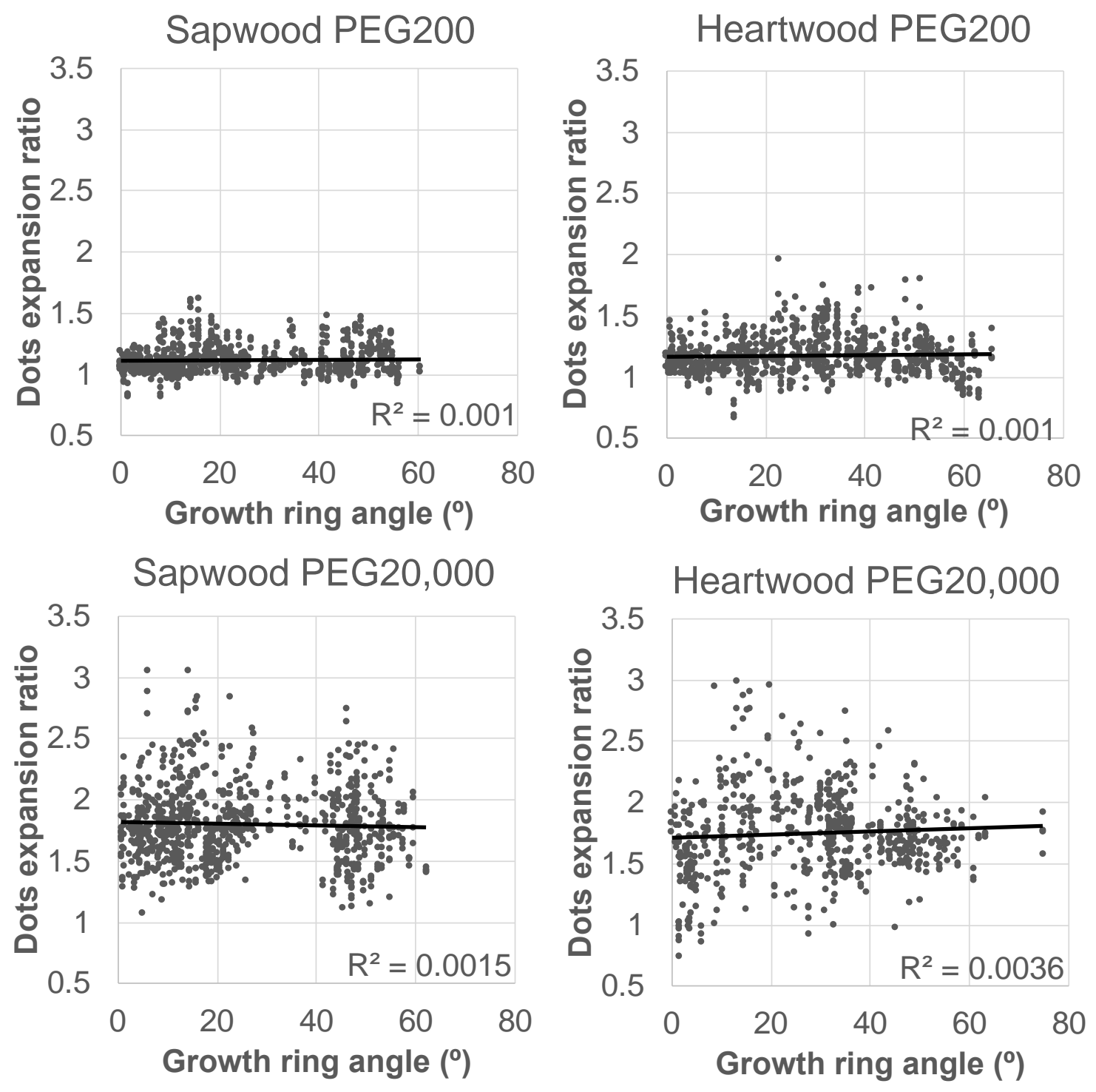

Fig. 6. Relationship between dots expansion ratio and growth ring angle 


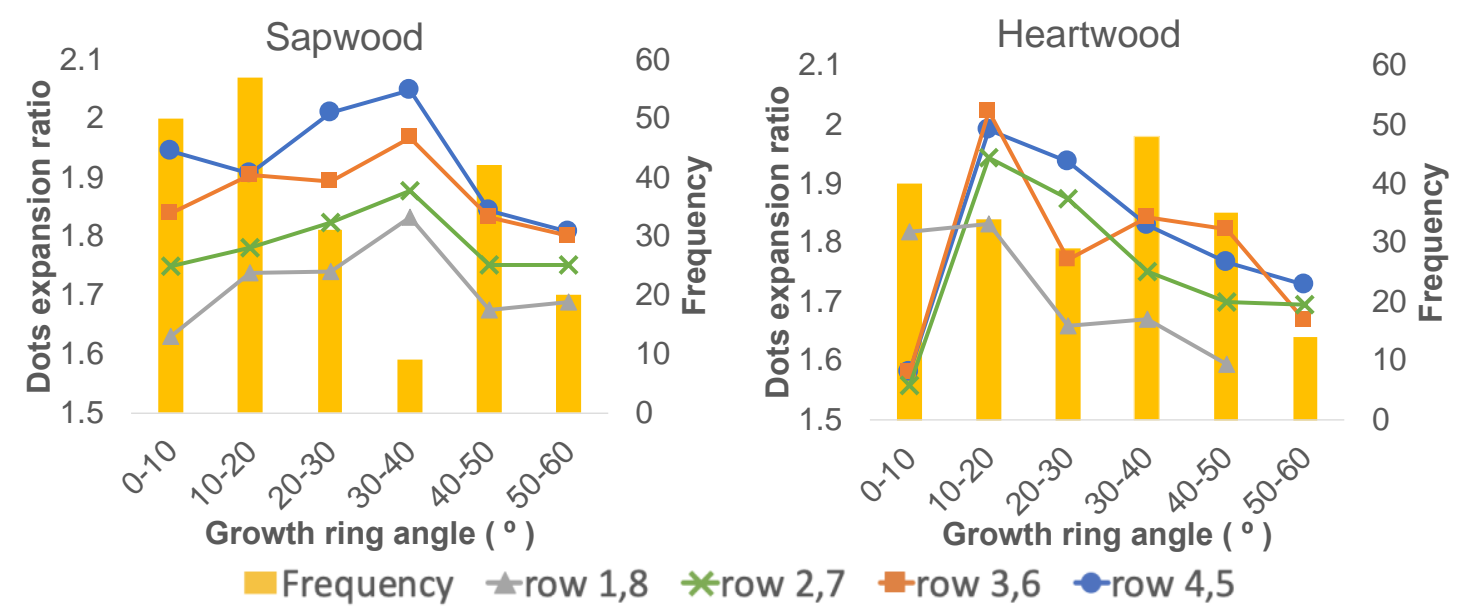

Fig. 7. Histogram of measured frequency and relationship between dots expansion ratio and growth ring angle treated with PEG20,000

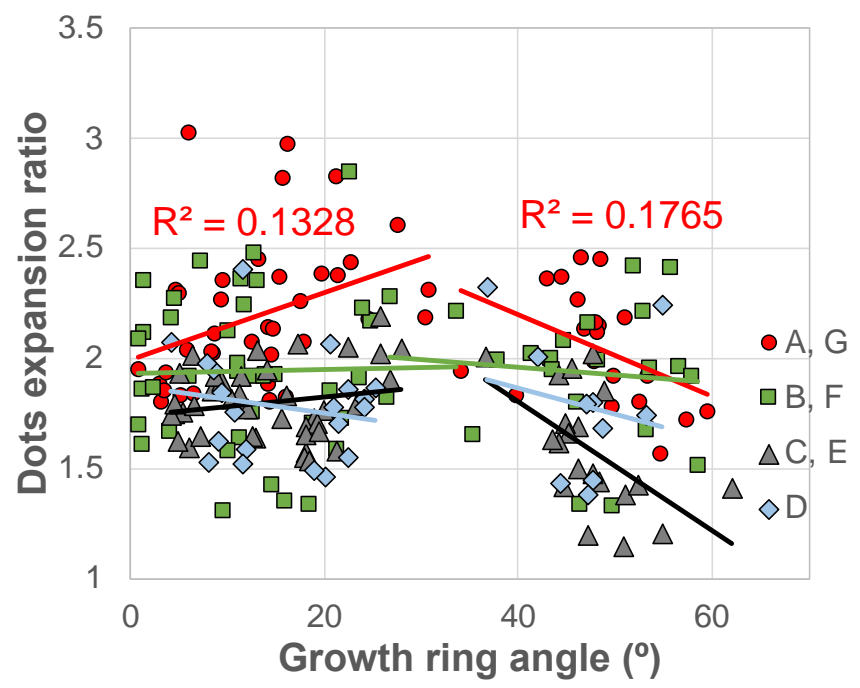

Fig. 8. Dots expansion ratio at 4 and 5 rows of sapwood specimens treated with PEG 20,000

To precisely investigate the relationship between the enlargement and the angle of growth ring, the local area between dots marked before and after compression were analyzed because the angle of growth ring was variable within a specimen. The relationship between them in heartwood and sapwood treated with PEG 200 and PEG 20,000 are shown in Fig. 6. The angle of the growth ring was selected from the closer cross surface of top or bottom. Areas where the length could not be measured (i.e. that were damaged and exploded during pressing), especially in heartwood, were removed. There was no correlation between the dots expansion ratio and the angle of growth rings of all specimens. However, when attention was paid to the widely varied dots expansion ratio of sapwood and heartwood treated with PEG20,000, some correlation might be contained within the large number of results, because the width enlargement on the center line was obviously larger than that on the both edge sides, as shown in Fig. 3 b.

Figure 7 shows the arranged results in Fig. 6. The dots expansion ratios collected from every symmetrical row on the center line (e.g. row 1 and 8) were averaged for every $10^{\circ}$ of growth ring, and a histogram was generated. The angles of the growth rings between the dots in the sapwood were clearly distributed between $0^{\circ}$ and $30^{\circ}$ of plane sawn 
specimens and $40^{\circ}$ and $60^{\circ}$ of $45^{\circ}$ sawn specimens. In comparison, the dots in heartwood specimens were dispersed due to their originating from logs for the smaller diameter of growth rings. There was a tendency that larger deformation occurred at the 4 and 5 rows corresponding to the center line for every angle of the growth rings in both sapwood and heartwood. However, no trend between deformation ratio and the angle of the growth rings was obtained.

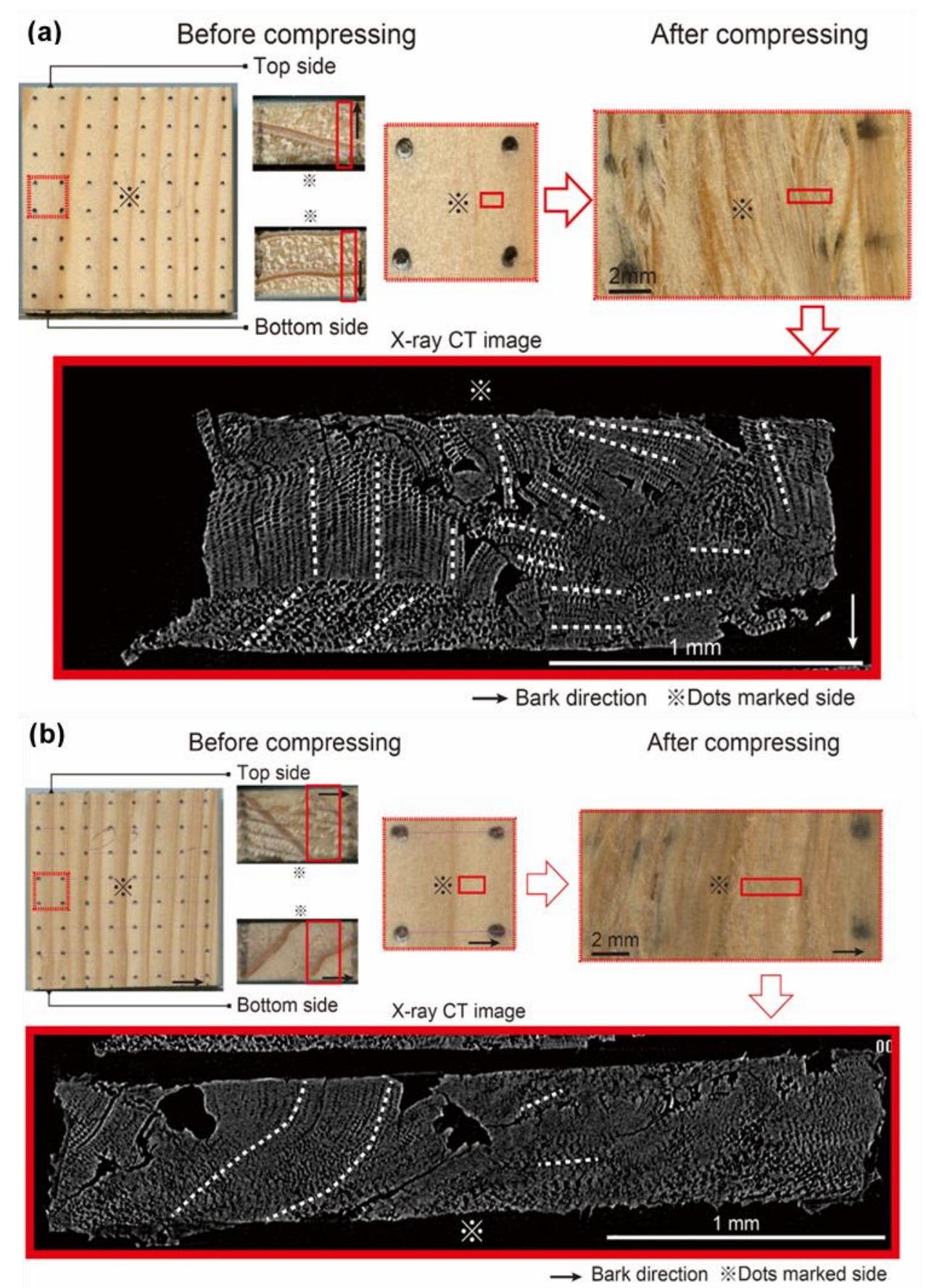

Fig. 9. X-ray CT image at column A in the center row of compressed wood. (a) Plane sawn board and (b) $45^{\circ}$ sawn board 
To investigate whether the angle of the growth ring affects enlargement, it is necessary to analyze a large deformed area where deformation is not restrained. Figure 8 shows the dots expansion ratio extracted from rows 4 and 5 of sapwood treated with PEG20,000, which showed the most width enlargement in this study. There was no correlation between the dots expansion ratio and the angle of the growth rings. However, the largest dots expansion ratios were derived from outside the specimen (red lines of column $\mathrm{A}$ and $\mathrm{G}$ in Fig. 2) rather than inside when approximately straight lines were drawn at each of the symmetrical columns (Fig. 8). Positive correlation in plane-sawn board, and the negative correlation in $45^{\circ}$ sawn board were contained in these areas showing the largest deformation rations, though these correlations were weak. The largest deformation was at approximately $35^{\circ}$, where two regression lines connected. Similar trends were obtained from heartwood specimens treated with PEG20,000. However, more research is necessary to support this conclusion because of few prepared specimens around $35^{\circ}$ in this study.

Micro-structure in the most enlarged area treated with PEG20,000 of sapwood was investigated using an X-ray micro CT. A single tomographic image at the cross section is shown in Fig. 9. A compressed mechanism was found based on the arrangement and deformation of cells. In plane-sawn board, enlargement was caused by the folded arrangement of cells on right side of the half (crosswise dots lines). However, radially arranged cells were observed in latewood and in compressed earlywood region on the left side of the half (vertical dots lines). In comparison, a uniform arrangement of cells was observed in the $45^{\circ}$ sawn board. From these results, it was found that the mechanism of enlargement differed depending on the direction of compression; the forced-out cells due to each cell moving in $45^{\circ}$ sawn board and the buckling of the radial cell arrangement arose from fast and excessive compression in plane sawn board. This morphological difference was considered to affect the width enlargement slightly; there was a weak correlation between the angle of the growth ring and dots expansion ratio in limited local area with the largest deformation.

\section{CONCLUSIONS}

1. Specimens treated with high molecular weight polyethylene glycol (PEG20,000) for both heartwood and sapwood were enlarged perpendicularly to fiber direction with the inflection points occurred in force-compression ratio curve, and there was no significant difference between the sawn types (plain and $45^{\circ}$ sawn) and width deformation ratio ( $p$-value>0.05). This enlargement was caused by compression exceeding the void volume, regardless of the wood density.

2. Larger deformations in the specimens were observed on the center line of the specimen perpendicular to fiber direction, for which both outer sides showed the most enlargement. The analysis of the correlation between the angle of the growth ring and dots expansion ratio in the largest deformed local areas showed weak positive and negative correlations for the plane-sawn boards and the $45^{\circ}$ sawn boards, respectively.

3. Images from an X-ray micro CT scan showed that the mechanism of enlargement differed depending on the direction of compression; the forced-out cells due to each cell moving in $45^{\circ}$ sawn board and the buckling of the radial cell arrangement arose from fast and excessive compression in plane sawn board. This morphological difference was considered to affect the weak correlation between the angle of the 
growth ring and local deformation ratio in limited local area with the largest deformation.

\section{ACKNOWLEDGMENTS}

The authors thank the staff of the Kasuya Research Forest of Kyushu University for providing the materials.

\section{REFERENCES CITED}

Bhushan, B. (2002). Introduction to Tribology, Wiley, New York.

Erickson, H. D. (1970). "Permeability of southern pine wood - A review," Wood Sci 2, 149-158.

Flynn, K. A. (1995). "A review of the permeability, fluid flow, and anatomy of spruce (Picea spp.)," Wood Fiber Sci. 27, 278-284.

Fujii, T., Suzuki, Y., and Kuroda, N. (1997). "Bordered pit aspiration in the wood of Cryptomeria japonica in relation to air permeability," IAWA J. 18(1), 69-76. DOI: 10.1163/22941932-90001462

Fukuta, S., Fumihiko, A., and Yasutoshi, S. (2008). "Manufacture of compressed wood fixed by phenolic resin impregnation through drilled holes," J. Wood Sci. 54, 100106. DOI: 10.1007/s10086-007-0920-x

Gao, Z., Huang, R., Lu, J., Chen, Z., Guo, F., and Zhan, T. (2016). “Sandwich compression of wood: Control of creating density gradient on lumber thickness and properties of compressed wood," Wood Sci. Tech. 50(4), 833-844. DOI: $10.1007 / \mathrm{s} 00226-016-0824-2$

Iida, I., Norimoto, M., and Imamura, Y. (1984). "Hygrothermal recovery of compression set," Mokuzai Gakkaishi 30, 354-358. (in Japanese)

Ioue, M., Aoki, T., and Egawa, G. (1992). "Development of a new teaching material utilizing recovery of compressive set of wood," Wood Research and Technical Notes 28, 59-71. (in Japanese) http://hdl.handle.net/2433/51454

Inoue, M., Kadokawa, N., Nishio, J., and Noritomo, M. (1993a). "Permanent fixation of compressive deformation by hygro-thermal treatment using moisture in wood," Wood Research and Technical Notes 29, 54-61. (in Japanese) http://hdl.handle.net/2433/51447

Inoue, M., Norimoto, M., Otsuka, Y., and Yamada, T. (1991). "Surface compression of coniferous wood lumber II. Permanent set of compression wood by low molecular weight phenolic resin and some physical properties of the products," Mokuzai Gakkaishi 37, 227-233. (in Japanese)

Inoue, M., Norimoto, M., Tanahashi, M., and Rowell, R. M. (1993b). "Steam or heat fixation of compressed wood," Wood Fiber Sci. 25, 224-235.

Inoue, M., Ogata, S., Kawai, S., Rowell, R. M., and Norimoto, M. (1993c). "Fixation of compressed wood using melamine-formaldehyde resin," Wood Fiber Sci. 25, 404410.

Maiti, S. K., Gibson, L. J., and Ashby, M. F. A. (1984). "Deformation and energy absorption diagrams for cellular solids," Acta Metall. 32, 1963-1975.

Miki, T., Nakaya, R., Seki, M., Tanaka, S., Sobue, N., Shigematsu, I., and Kanayama, K. 
(2017). "Large deformability derived from a cell-cell slip mechanism in intercellular regions of solid wood," Acta Mech. 228, 2751-2758. DOI:10.1007/s00707-015-1523-z

Miki, T., Seki, M., Shigematsu, I., and Kanayama, K. (2014a). "Preparation of three dimensional products using flow deformability of wood treated by small molecular resins," Adv. Mat. Res. 856, 79-86. DOI: 10.4028/www.scientific.net/AMR.856.79

Miki, T., Seki, M., Tanaka, S., Sobue, N., Shigematsu, I., and Kanayama, K. (2014b). "Preparation of wood plastic composite sheets by lateral extrusion of solid woods using their fluidity," Procedia Eng. 81, 580-585. DOI: 10.1016/j.proeng.2014.10.043

Miki, T., Sugimoto, H., Shigematsu, I., and Kanayama, K. (2014c). "Superplastic deformation of solid wood by slipping cells at sub-micrometre intercellular layers," Int. J. Nanotechnol. 11, 509-519. DOI: 10.1504/IJNT.2014.060572

Nagai, S., and Taniguchi, Y. (2001). "Air permeability in wood of Cryptomeria japonica D. Don: Air permeability in heartwood, white zone wood and sapwood in green logs," J. Soc. Mat. Sci. Japan 50, 409-414. DOI: 10.2472/jsms.50.409

Reiterer, A., and Stanzl-Tschegg, S. E. (2001). "Compressive behaviour of softwood under uniaxial loading at different orientations to the grain," Mech. Mat. 33, 705-715. DOI: 10.1016/S0167-6636(01)00086-2

Stribeck, R. (1902). “Die wesentlichen Eigenschaften der Gleit-und Rollenlager," Z. Ver Dtsching. 46, 1341-1348.

Tarkow, H., Feist, W. C., and Southerland, C. F. (1966). "Interaction of wood with polymeric materials penetration versus molecular size," For. Prod. J. 16, 61-65

Wallström, L., and Lindberg, K. A. H. (1999). "Measurement of cell wall penetration in wood of water-based chemicals using SEM/EDS and STEM/EDS technique. Wood Sci. Technol. 33, 111-122. DOI: 10.1007/s002260050103

Watanabe, U., Imamura, Y., and Iida, I. (1998). "Liquid penetration of precompressed wood VI: Anatomical characterization of pit fractures," J. Wood Sci. 44(2), 158-162. DOI: $10.1007 / \mathrm{BF} 00526263$

Wood Handbook. (2010). "Mechanical properties of wood," in Wood as an Engineering Material, United States Department of Agriculture Forest Service, Forest Products Laboratory, Madison, WI. DOI: 10.2737/FPL-GTR-190

Article submitted: August 18, 2020; Peer review completed: September 5, 2020; Revised version received and accepted: September 15, 2020; Published: October 5, 2020.

DOI: 10.15376/biores.15.4.8756-8769 